\title{
Hypertension as the Major Cause of Stroke
}

\author{
Blas Gil-Extremera ${ }^{*}$ and Juan Vicente Gómez-González ${ }^{2}$
}

${ }^{1}$ Hypertension and Lipid Unit, Service of Internal Medicine, San Cecilio University Hospital, University of Granada, Granada, Spain

${ }^{2}$ Critical Care Unit and Emergency Department, Poniente Hospital. El Ejido, Almería, Spain

Received: July 29, 2014; Accepted: March 29, 2015; Published: April 10, 2015

*Corresponding author: Blas Gil-Extremera, Hypertension and Lipid Unit, Service of Internal Medicine, San Cecilio University Hospital, University of Granada, Spain, Tel: + 349582490 81; E-mail: blasgil@ugr.es

\begin{abstract}
The aim of this manuscript was to point out the relevance of the clinical aspects of stroke based on several clinical studies. We carried out a retrospective data collection study in 433 patients with cerebrovascular disease,which represent $7 \%$ of all patients admitted to our Service of Internal Medicine between 1979-1985. In this particular study the most frequent risk factor found was hypertension, $64.7 \%$ which represents the total median value (in men and women) of Transient Ischemic Attack (TIA), full stroke, and stroke in evolution. In another recent cross-sectional investigation carried out in 243 patients admitted with ischemic stroke, the most common modifiable risk factors were hypertension $(72.1 \%)$, followed by diabetes (51.7\%), and dyslipidemia(28.5\%). Patients older than 60 years with isolated systolic hypertension constitutes a special group of population susceptible to disorders of the central nervous system. In our experience,a more effective antihypertensive treatment is needed to prevent this serious clinical situation in these patients.
\end{abstract}

Keywords: Hypertension; Stroke; Age; Risk factors; Cardiovascular disease; Cerebrovascular events; Ageing; Isolated Systolic Hypertension; Ischemic stroke; Intracerebral hemorrhage; Transient Ischemic Attack; Vascular neurologic dysfunction; Embolism; Thrombosis; Bleeding; Atherosclerosis; Diabetes mellitus; Dyslipidemia; Tobacco; Alcohol abuse; Obesity; Cardiac dysrhythmia; Semiology of stroke; Vascular dementia; Cerebral disease; Non modifiable risk factors; Arterial circle or Willis hexagon

\section{Introduction}

Levels of Blood Pressure (BP) higher than normal $(\leq 130 / 80 \mathrm{mmHg})$ is the most important public health problem in developed countries. It is important to realize that it is commonly asymptomatic, easy to detect, but difficult to control, and often leads to acute lethal complications, such as stroke. It is a devastating disease and is responsible for a transient or permanent neurologic dysfunction secondary to ischemic or hemorrhagic mechanisms of the Central Nervous System (CNS) [1]. Terminology and classification of stroke had already established according to the etiology [2]. There are several terms to define the presentation of this pathology in the clinical practice; the most adequate term should be cerebrovascular disease, mainly due to circulatory system problems (embolism, thrombosis, or hemorrhage) responsible for producing lesions occasionally irreversible. Arterial circle, polygon or Willis hexagon, supplies blood to the encephalon. It was described by the English clinician Thomas Willis (1622-1673).This author was also the first to describe myasthenia gravis and puerperal fever.

At present, epidemiological analyses are able to quantify the risk factors responsible for cardiovascular diseases [3], age [4], hypertension, and history of previous heart disease [5-7]. Nevertheless, the principal etiology of stroke is atherosclerosis: a combination of circumstances affecting the arterial wall responsible for the inadequate supply of blood to the CNS. According to the general clinical opinion, the risk factors are classified into three categories: a) modifiable risk factors, (hypertension (72.1\%), diabetes, dyslipidemia, arrhythmia, tobacco, alcohol abuse ( $>5$ drinks daily) $(8.1 \%)$, obesity $(8.1 \%)$, and uncommon cause $(25.6 \%)$; b) non modifiable risk factors (age, gender, ethnic groups, history of cardiovascular disease), and c) unknown circumstances.

\section{Our Experience}

Isolated Systolic Hypertension (ISH) is defined as Systolic Blood Pressure (SBP) $\geq 160 \mathrm{mmHg}$ and Diastolic Blood Pressure (DBP) $\leq 90 \mathrm{mmHg}$. This situation affects $5 \%$ of the population older than 60 years, $13 \%$ of patients older than 70 years, and $24 \%$ of patients $\geq 80$ years [8]. Some observational studies have demonstrated that the incidence of stroke and myocardial infarction in elderly people was strongly related to the levels of SBP; conversely, DBP levels do not represent an important predictor of risk [9]. However, the treatment of patients with both systolic and diastolic BP elevation reduces the incidence of cerebrovascular disease and all cardiovascular events combined. The hypothesis that antihypertensive drugs should also be prescribed to elderly population with ISH has been proven in at least three big clinical trials: SHEP (Systolic Hypertension in the Elderly Program), SYST-EUR Study (Systolic Hypertension in Europe), and HYVET (Hypertension in the Very Elderly Trial).

The SHEP trial showed a significant benefit for non-fatal stroke, but fatal strokes were not significantly reduced. The incidence of fatal strokes was rather low in the SHEP's control group (14 of 159 strokes without including transient ischemic attacks, 9\%). Whether the low incidence of fatal strokes in the 
SHEP trial is the results of the healthy patient effect or is due to the classification of a number of very mild cerebrovascular accidents as stroke remains still unknown [8]. Furthermore, the fate of some stroke survivors was not yet been reported. It may be important to know how many stroke survivors have fully recuperated, how many remained incapacitated, and how many will eventually die from other causes during later follow-up [9].

This information is based on our large clinical experience in patients admitted to our Service of Internal Medicine and those referred from the Hypertension and Lipid Unit, as well as on several own studies [10-17]. In one of our researches [10] we analyzed retrospectively, 433 cases of stroke that represent $7 \%$ of all patients admitted to our Service of Internal Medicine between 1979 and 1985. The following were the conclusion of this investigation: most of the patients (men and women) were between 65 and 75 years old; the most frequent risk factors were hypertension $74.3 \%, 75.7 \%$, and $54.2 \%$, in men for TIA, full stroke, and stroke in evolution, respectively, and values of $70 \%, 62.2 \%$, and $51.8 \%$ in women for TIA, full stroke, and stroke in evolution respectively; the median values for cardiac dysrhythmia were $35 \%$ and $35.2 \%$ in men and women, respectively, and the median values for diabetes mellitus were $36.9 \%$ and $21.8 \%$ in men and women respectively [10] (Detailed values are shown in table 1). The prevalence of cerebral risk factors in our patients is shown in table 2). These previous discouraging results from our population were however, the motivation to create our Hypertension Unit in order to ameliorate this devastating clinical situation, not only in our region but also probably in everywhere. After that point and so far, we have treated thousands of patients with cardiovascular risk (hypertensive, diabetic, dyslipidemic patients and others) with the important and ambitious goal to improve this deteriorated situation. After that time, our group has also participated in more than 150 international clinical trials to improve the prognosis of this disease; even if the situation is now getting much better than three decades ago, there are still many problems to be resolved.

The recent study [11] was an observational cross-sectional investigation about the incidence of patients with ischemic cardiovascular disease carried out between June 2005 and June 2006. The study enrolled 243 patients in a referral population of 250,000 individuals from the province of Almeria (Spain). 172 individuals were diagnosed with acute ischemic stroke. All these patients with stroke were admitted to the Emergency and Critical Care Unit (1\% of the population) because of ischemic cerebrovascular disease (neurological deficit lasting more than 24 hours of ischemic origin) with an incidence of 69 per 100,000 individuals per year. The semiology developed in the patients shown in table 3 . The prevalence of stroke according to age shown in table 4. Although age is a risk factor for stroke events affecting mostly people older than 65 years, our experience reveals that this pathology is found in younger immigrants coming from the African continent (countries belonging to the Sub-Saharan region). The study was carried out according to the recommendations of the $59^{\text {th }}$ General Assembly, Seul, 2008, and by the Convention for the Protection of Human Rights and
Table 1: Previous risk factors in stroke patients.

\begin{tabular}{|l|c|c|c|c|c|c|}
\hline \multicolumn{1}{|c|}{ Disorder } & \multicolumn{2}{|c|}{ TIA(\%) } & \multicolumn{2}{|l|}{$\begin{array}{l}\text { Full } \\
\text { Stroke(\%) }\end{array}$} & \multicolumn{2}{l|}{$\begin{array}{l}\text { Stroke In } \\
\text { Evolution(\%) }\end{array}$} \\
\hline & M & W & M & W & M & W \\
\hline HT (64.7\%) & 74.3 & 70 & 75.7 & 62.2 & 54.2 & 51.8 \\
\hline Diabetes & 40.5 & 13.3 & 30.8 & 17.8 & 39.5 & 34.5 \\
\hline $\begin{array}{l}\text { Cardiac } \\
\text { Dysrhythmia }\end{array}$ & 40.5 & 36.6 & 35.5 & 34.0 & 29.2 & 35.2 \\
\hline Heart Failure & 21.6 & 30.0 & 31.8 & 17.8 & 29.2 & 24.1 \\
\hline
\end{tabular}

$\mathrm{M}=\mathrm{Men} ; \mathrm{W}=$ women; TIA = Transient Ischemic Attack; HT $(64.7 \%)^{*}=$ Total median value for hypertension

Table 2: Prevalence of patients with cerebrovascular risk factors in our Service of Internal Medicine.

\begin{tabular}{|l|l|}
\hline Modifiable risk factors & $\begin{array}{l}\text { Prevalence } \\
\text { (\%) }\end{array}$ \\
\hline Hypertension & 72.1 \\
\hline Diabetes & 51.7 \\
\hline Dyslipidemia & 28.5 \\
\hline Arrhythmia & 22.1 \\
\hline Tobacco use & 20.3 \\
\hline Alcohol consumption (>5 drinks daily) & 8.1 \\
\hline Obesity & 5.8 \\
\hline Other uncommon or unknown risk factors & 25.6 \\
\hline
\end{tabular}

Table 3: Semiology of patients before stroke development.

\begin{tabular}{|l|c|c|c|c|c|c|}
\hline \multicolumn{1}{|c|}{ Symptoms } & \multicolumn{3}{|c|}{ TIA(\%) } & \multicolumn{2}{l|}{$\begin{array}{l}\text { Full } \\
\text { Stroke(\%) }\end{array}$} & \multicolumn{2}{l|}{$\begin{array}{l}\text { Stroke In } \\
\text { Evolution(\%) }\end{array}$} \\
\hline & $\mathbf{M}$ & $\mathbf{W}$ & $\mathbf{M}$ & $\mathbf{W}$ & $\mathbf{M}$ & $\mathbf{~ W}$ \\
\hline Headache & 32.4 & 23.3 & 28.9 & 25.5 & 29.2 & 27.8 \\
\hline Intelectual disturbances & 13.5 & 18.3 & 4.7 & 5.5 & 20.9 & 3.7 \\
\hline Insomnia & 12.1 & 6.7 & 4.7 & 7.8 & 4.2 & 9.2 \\
\hline Dizziness & 16.4 & 15.0 & 14.0 & 11.1 & 18.7 & 18.6 \\
\hline
\end{tabular}

TIA: Transient Ischemic Attack; $M=$ men; $W$ = women

Table 4: Prevalence of stroke (hemorrhagic or ischemic) according to age.

\begin{tabular}{|l|c|c|c|}
\hline Age & \multicolumn{2}{|c|}{$\begin{array}{l}\text { Prevalence } \\
\text { (\%) }\end{array}$} & \multicolumn{2}{|l|}{$\begin{array}{l}\text { Hemorrhagic stroke } \\
\text { (\%) }\end{array}$} & \multicolumn{2}{l|}{$\begin{array}{l}\text { Ischemic stroke } \\
\text { (\%) }\end{array}$} \\
\hline $18-50$ & $2.7 \%$ & $100 \%$ & $0 \%$ \\
\hline $51-65$ & $38.4 \%$ & $50 \%$ & $50 \%$ \\
\hline $66-99$ & $58.9 \%$ & $18 \%$ & $82 \%$ \\
\hline
\end{tabular}

Dignity of the Human Being.

Patients aged between 18 and 50 years presented hemorrhagic stroke in $100 \%$ of the cases. However, these patients represent only $2.7 \%$ of the total strokes for all ages. These results can not be compared to other studies, given the special characteristics of this region of Almería, Spain, where there are many young African immigrants with uncontrolled, severe hypertension, who presented with hemorrhagic stroke. 
We found an increasing prevalence of ischemic stroke with age: the prevalence of hemorrhagic and ischemic stroke was similar in patients between $51-65$ years ( $50 \%$ vs $50 \%$ ); however, the prevalence of ischemic stroke was found to be much higher in older patients (between 66-99 years) (Table 4).

The inclusion criteria for our patients were:

- No age limit;

- People going to the Emergency room on one's own initiative, or referred from Primary Care Unit or the Emergency medical services (DECU, 061);

- Reason for consultation- deficient neurological symptoms or signs, lasting more than 24 hours, and later admission to the Service of Internal Medicine or Intensive Care Unit;

- Physical examination and initial complementary tests suggesting acute stroke;

- For diagnostic process CAT scan should be performed for Cranioencephalic trauma.

The exclusion criteria includes three particular points:

- Patients diagnosed with transient ischemic stroke;

- Patients diagnosed with hemorrhagic stroke (they were referred to the Referral Hospital of Torrecardenas, in Almería)

- Cases of hemorrhagic stroke rejected for neurosurgery treatment.

The statistical analysis was performed using SPSS Version 10.1; Student's t-test was employed for continuous variables and Chi-Square for discrete variables. Comparisons are made in two ways such as one-way analysis of variance was used for quantitative variables; when significant, paired comparisons were carried out according to the Bonferroni method. Contingency tables are performed for qualitative variables; Chisquare test and Fisher's test were used for contingency tables. $\mathrm{P}$ value of $<0.05$ was considered significant in all tests.

A number of medical interventions as well as lifestyle modifications and the control for modifiable risk factors are available to reduce the incidence and prevalence of cardiovascular disease. It is especially important for the early diagnosis of acute episodes of the disease by the therapeutic procedures in the interim of 3-6 hours after the onset of stroke symptoms during the penumbra period, in order to reduce functional sequela and the high socioeconomic impact of stroke. It is important for the physicians to know the clinical, epidemiological and therapeutic characteristics of cerebral ictus not only in older population but also in young people, particularly, in our case, the increasing number of African immigrants in the South of Spain.

Hemorrhagic stroke is the most common type of non traumatic intracranial bleeding events provoked by different causes such as hypertension, amyloid angioplasty, aneurysm breakage, systemic bleeding disorders, cocaine, or amphetamines consumption. In our patients, intracerebral hemorrhage was more frequent in the young population, while obviously, ischemic stroke was present mostly in older population, subsequent to atherosclerotic blood vessels. In younger people cocaine, abuse and aneurysm are the cause responsible for the disease.

In the third part of this paper, we report our experience on hypertension associated with increased risk of both vascular dementia and Alzheimer disease [12,13]. Because of the increasing longevity of the population worldwide, prevention of dementia has turned into a major public health problem. Randomized double blind placebo-controlled Systolic Hypertension in Europe (Syst-Eur) trial, our Hypertension Unit, and other 18 European countries have participated in the study. We found that compared with placebo, treatment with antihypertensive drugs -enalapril, nitrendipine, hydrochlorothiazide or all- reduced the incidence of dementia by $50 \%$ from 7.7 to 3.8 cases per 1000 patient-years ( 21 vs. 11 cases). These findings are the results of 106 selected centers in Europe, with 3228 patients enrolled in the study; nevertheless, nine patients had dementia at baseline, whereas in 59 patients cognitive impairment could not be excluded. It is crucial to find a protective mechanism to supply blood flow to vital organs. In older population with isolated systolic hypertension and patients older than 80 years, the incidence of cardiovascular disease, peripheral arterial disease, sudden death, and others problems should not be ignored [15-17].

\section{Acknowledgments}

We thank Mrs. Esperanza Velasco for the English translation of the manuscript.

\section{References}

1. ALLHAT Officers and Coordinators for the ALLHAT Collaborative Research Group. The Antihypertensive and Lipid-Lowering Treatment to Prevent Heart Attack Trial. Major outcomes in high-risk hypertensive patients randomized to angiotensin converting enzyme inhibitor or calcium channel blocker vs diuretic: The antihypertensive and Lipid Lowering Treatment to Prevent Heart Attack Trial (ALLHAT). JAMA. 2002; 288(23): 2981-97.

2. Jørgensen HS, Nakayama H, Pedersen PM, Kammersgaard L, Raaschou HO, Olsen TS. Epidemiology of stroke-related disability.The Copenhagen Stroke Study, Clin Geriatr Med. 1999;15(4): 785-99.

3. Castilla-Guerra L, Fernández Moreno MC, Álvarez-Suero J. Ictus cardioembólico.Rev Clin Esp. 2010; 210: 127-32. DOI: 10.1016/j. rce.2009.07.003.

4. Boix R, Del Barrio JL, Saz P, Rene R, Manubens JM, Lobo A ,et al. Stroke prevalence among the Spanish elderly: an analysis based on screening surveys. BMC Neurol. 2006; 6: 36.

5. Arboix A. Registros de enfermedades vasculares cerebrales. Med Clin (Barc). 2008; 130: 623-625. doi: 10.1157/13120354.

6. Epstein D, Mason A, Manca A. The hospital cost of care for stroke in nine European countries. Health Econ. 2008; 17(1 Suppl): S21-31. doi: 10.1002/hec.1329.

7. Di Carlo A, Launer LJ, Breteler MMB, Fratiglioni L, Lobo A, MartinezLage J, et al. Frequency of stroke in Europe:a collaborative study of population-based cohorts.ILSA Working Group and the Neurologic Diseases in the Elderly Research Group. Italian Longitudinal Study on Aging. Neurology. 2000; 54(11 Suppl 5): S28-33. 
8. Prevention of stroke by antihypertensive drug treatment in older persons with isolated systolic hypertension. Final results of the Systolic Hypertension in the Elderly Program (SHEP). SHEP Cooperative Research Group. JAMA. 1991; 265(24): 3255-64.

9. Staessen JA, Fagard R, Amery A. Isolated Systolic Hypertension in the Elderly: implications of SHEP for clinical practice and for the ongoing trials. J Hum Hypertens. 1991; 5(6): 469-74.

10. Gómez Leyva A, Gil Extremera B, Cantero Hinojosa J, Guzman Regueiro G. Enfermedad cerebrovascular. Estudio de 433 casos en la provincia de Granada (1979-1985). An Med Intern (Mad). 1988; 5: 327-332.

11. Gómez González JV, Gil Extremera B. Ischemic stroke: complication of Hypertension in hospital West of Almería in Spain.Family Medicine and Community Health. 2013; 1: 8-13.

12. Forette F, Seux MC, Staessen JA, Thijs L, Babarskiene MR, Gil Extremera B, et al. The prevention of Dementia with Antihypertensive Treatment: New Evidence from the Systolic Hypertension in Europe (Syst-Eur) Study. Arch Intern Med. 2002; 162(18): 2046-52.
13. Forette F, Seux ML, Staessen JA, Thijs L, Birkenhäger WH, Gil Extremera $B$, et al. Prevention of Dementia in randomized double-blind placebocontrolled Systolic Hypertension in Europe (Syst-Eur Trial). Lancet. 1998; 352(9137): 1347-51.

14. Gil Extremera B. Isolated Systolic hypertension. The Hypertension Letter. 1998; 32: 2-3.

15. Bulpitt ChJ, on behalf of the HYVET investigators. The Hypertension in the Very Elderly Trial: the importance of the pilot trial and modifications to the protocol. Eur Heart J. Suppl 1999; 1: 9-12.

16. Bulpitt ChJ, Beckett NS, Cooke J, Dumitrascu DL, Gil Extremera B, Nachev C, et al. Results of the pilot study for the Hypertension in the Very Elderly Trial. J Hypertens. 2003; 21(12): 2409-17.

17. Beckett NS, Peters R, Fletcher AE, Staessen JA, Liu L, Dumitrascu D, et al. Treatment of Hypertension in patients 80 years of Age or Older. N Engl J Med. 2008; 358(18): 1887-98. doi: 10.1056/NEJMoa0801369. 